\title{
Cenários de instituições de longa permanência para idosos: retratos da realidade vivenciada por equipe multiprofissional
}

\author{
Scenery of long-term care institutions: portraits of the routine of a multiprofessional team
}

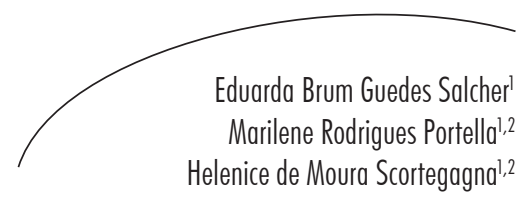

\section{Resumo}

Objetivo: Identificar os desafios e perspectivas de trabalho nas instituições de longa permanência para idosos (ILPI) na interpretação da equipe multiprofissional. Metodologia: Estudo de abordagem qualitativa, exploratória e descritiva, recorte da pesquisa intitulada "Cenários de cuidados de longa duração: possibilidades avaliativas, interventivas e educacionais na atenção gerontológica". A pesquisa foi desenvolvida no município de Passo Fundo-RS, de março a agosto de 2013, contemplando 14 ILPIs. Resultados: As situações desafiadoras do trabalho aludem ao aspecto de gestão, sistematização de ações, manutenção, convivência e mediação de conflitos profissionais e interpessoais, e no que se refere ao paradigma da institucionalização. As perspectivas da atuação em ILPIs correspondem à valorização com inserção profissional nos cenários de atenção, considerando a Gerontologia especialidade emergente no cumprimento dos preceitos legais e com maior incentivo do poder público. Conclusões: Os desafios são múltiplos e de ordem diversa. A perspectiva é que, num futuro próximo, possa existir uma equipe multiprofissional mais homogênea atendendo à legislação vigente.

\section{Abstract}

Objective: To identify the challenges and prospects of work in long-term institutions for the elderly (ILPI) in the viewpoint of the multidisciplinary team. Methodology: Qualitative, exploratory and descriptive study, part of a research entitled "Scenarios of long-term care: evaluative, intervention and educational possibilities in geriatric attention". Research was conducted in the city of Passo Fundo-RS, Brazil, from March to August 2013, involving 14 ILPI's. Results: The challenging situations at work allude to management aspect, systematic actions, maintenance, coexistence and mediation of professional and interpersonal conflicts, as well as to the institutionalization paradigm.
Palavras-chave: Avaliação da Capacidade de Trabalho. Equipe de Cuidados de Saúde. Instituições de Longa Permanência para Idosos. Satisfação no Trabalho.
Key words: Work Capacity Evaluation. Patient Care Team. Homes for the Aged. Job Satisfaction.

Universidade de Passo Fundo, Faculdade de Educação Física e Fisioterapia, Programa de Pós-graduação em Envelhecimento Humano. Passo Fundo, RS, Brasil.

2 Universidade de Passo Fundo, Instituto de Ciências Biológicas, Curso de Enfermagem. Passo Fundo, RS, Brasil. 
The appreciation of professionals based on their insertion in health care settings makes gerontology an emerging specialty with greater encouragement of public power. Conclusions: The challenges are multiple and of different origins. It is expected that, in the near future, a more homogeneous multidisciplinary team attending current legislation becomes possible.

\section{INTRODUÇÃo}

A transição demográfica, as baixas taxas de fecundidade, o aumento da expectativa de vida, a inserção da mulher no mercado de trabalho e as novas configurações familiares apontam para um cenário de preocupação no que reporta à necessidade de cuidado das pessoas envelhecidas. ${ }^{1,2}$ Nessa conjuntura de transformações sociais, nem sempre a família dispõe de um cuidador quando um dos seus membros idosos requer apoio e/ou auxílio direto. Assim, as instituições de longa permanência para idosos (ILPI) surgem como alternativa de cuidado fora do âmbito familiar. ${ }^{3}$

As ILPIs têm o caráter residencial, na forma de domicílio coletivo para pessoas com idade igual ou superior a 60 anos, com ou sem suporte familiar, ${ }^{4}$ abrigando residentes com características de saúde distintas, portadores de problemas de saúde em condição crônica e incapacitante e, nesta condição, o cuidado deve seguir a perspectiva geronto-geriátrica. ${ }^{5}$

O regulamento técnico que consta na Resolução de Diretoria Colegiada (RDC) $\mathrm{n}^{\circ}$ $283^{4}$ define normas de funcionamento para as ILPIs e sinaliza que tais instituições são entidades sociais, destinadas à prestação de serviço ao idoso, contemplando atenção aos indivíduos independentes até aqueles cujo grau de dependência requeira assistência em todas as atividades de autocuidado para a vida diária e com comprometimento cognitivo. ${ }^{4}$

Importante chamar atenção para o fato de que as ILPIs, mesmo não tendo caráter, foco e denominação exclusiva de serviço de saúde, ${ }^{6}$ cedem à demanda da assistência à saúde em função do grau de dependência dos idosos residentes. Essa conjuntura perpassa a visão generalista, com extensão das ações especializadas, em decorrência do grande contingente com doenças incapacitantes e demências, ${ }^{7}$ demanda emergente frente às condições sociodemográficas contemporâneas. ${ }^{8}$

A complexidade que envolve o fenômeno do envelhecimento e as demandas de cuidado provenientes das condições de saúde dos idosos requerem ações que contemplem a interdisciplinaridade nos serviços de saúde, em todos os níveis de atenção, incluindo nessa premissa o contexto das instituições de longa permanência.?

A ILPI, segundo os preceitos legais, deve apresentar recursos humanos com vínculo formal de trabalho ou terceirizados, que garantam a realização de atividades de cuidados aos residentes, conforme grau de dependência; de lazer, executada por profissional com formação de nível superior; além dos serviços de limpeza, alimentação e lavanderia. ${ }^{4}$ Para que o processo de trabalho seja qualificado nesses cenários, a equipe multiprofissional deve ser composta por enfermeiro, técnicos de enfermagem, médico, nutricionista, psicólogo, assistente social, fisioterapeuta e educador físico, além dos

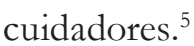

No que se refere à equipe multidisciplinar dentro das ILPIs, compreende-se que sua importância repousa na necessidade de proporcionar aos idosos residentes um cuidado ampliado na busca de atender a um conjunto de necessidades, assegurando ao idoso uma atenção integral a sua saúde. A partir dessa compreensão, tem-se como pressuposto que um dos maiores 
desafios da assistência multidisciplinar à pessoa idosa é propiciar que múltiplas áreas do saber ajam conjuntamente, tendo um olhar multidimensional. ${ }^{10}$

O trabalho em equipe, ao valorizar a interface presente na multiprofissionalidade, possibilita a comprovação de uma atenção que se desloca do eixo recortado e reduzido / corporativo - centrado para o eixo - plural e complexo / usuário-centrado. ${ }^{11}$

Alguns estudos sobre as ILPIs brasileiras, ${ }^{8,12,13}$ em especial aqueles que abordam a questão no Sul do país, ilustram uma realidade em que predominam instituições filantrópicas destinadas a idosos de baixa renda, recursos humanos insuficientes para acolher a demanda e dificuldades de manter uma equipe multiprofissional que atenda às especificidades da legislação vigente. Nesse sentido, este estudo discute a composição das equipes de saúde, frente às dificuldades e a problemática que envolve o cuidado em saúde do idoso institucionalizado, com o objetivo de identificar os desafios e perspectivas de trabalho nas instituições de longa permanência para idosos, na interpretação da equipe multiprofissional.

\section{METODOLOGIA}

Estudo de abordagem qualitativa, exploratório-descritivo, é um recorte da pesquisa intitulada "Cenários de cuidados de longa duração: possibilidades avaliativas, interventivas e educacionais na atenção gerontológica". A pesquisa foi desenvolvida no município de Passo Fundo-RS, no período de março a agosto de 2013, contemplando 14 ILPIs.

Após contato prévio com os gestores das ILPIs e os profissionais das suas equipes, por meio de visita dos pesquisadores responsáveis às instituições, deu-se a entrada no campo de estudo. Foram convidados todos os profissionais, de diferentes categorias da área da saúde que atuam nas ILPIs, sendo considerados como participantes aqueles que compõem a equipe que atua em cada ILPI que deram seu aceite mediante assinatura do Termo de Consentimento Livre e Esclarecido, totalizando 38 profissionais (enfermeiros, nutricionistas, educadores físicos, fisioterapeutas e psicólogos).

A coleta de dados, realizada por meio de entrevista individual a partir de instrumento semiestruturado, gerou um banco de dados do qual foram utilizados os dados que registraram as respostas sobre características gerais do entrevistado e aspectos da formação, e também sobre a organização dos serviços, para a descrição do perfil dos participantes. Os dados referentes às questões dos desafios enfrentados na atuação em ILPI, bem como as perspectivas futuras em relação à profissão nesse cenário, foram submetidos à análise categorial de conteúdo. ${ }^{14}$

As entrevistas, gravadas em áudio digital e transcritas na íntegra, foram realizadas nas ILPIs, em data e horário agendados previamente com os profissionais, segundo a disponibilidade e conveniência individual, por alunos do Programa de Pós-Graduação em Envelhecimento Humano e do Curso de Graduação em Enfermagem da Universidade de Passo Fundo (UPF), membros do Grupo de Pesquisa Vivencer CNPq/UPF, que receberam instruções e treinamento prévios.

Os aspectos éticos foram contemplados pela aprovação do Comitê de Ética em Pesquisa da Universidade de Passo Fundo, mediante protocolo no 393/2011, e posteriormente pela sujeição às diretrizes da Resolução no 466/12, do Conselho Nacional de Saúde, sobre a participação de pessoas em pesquisas.

\section{RESULTADOS E DISCUSSÃO}

A equipe multiprofissional encontrada nos cenários de cuidados de longa duração é composta de cinco categorias profissionais, conforme mostra a figura 1 . 


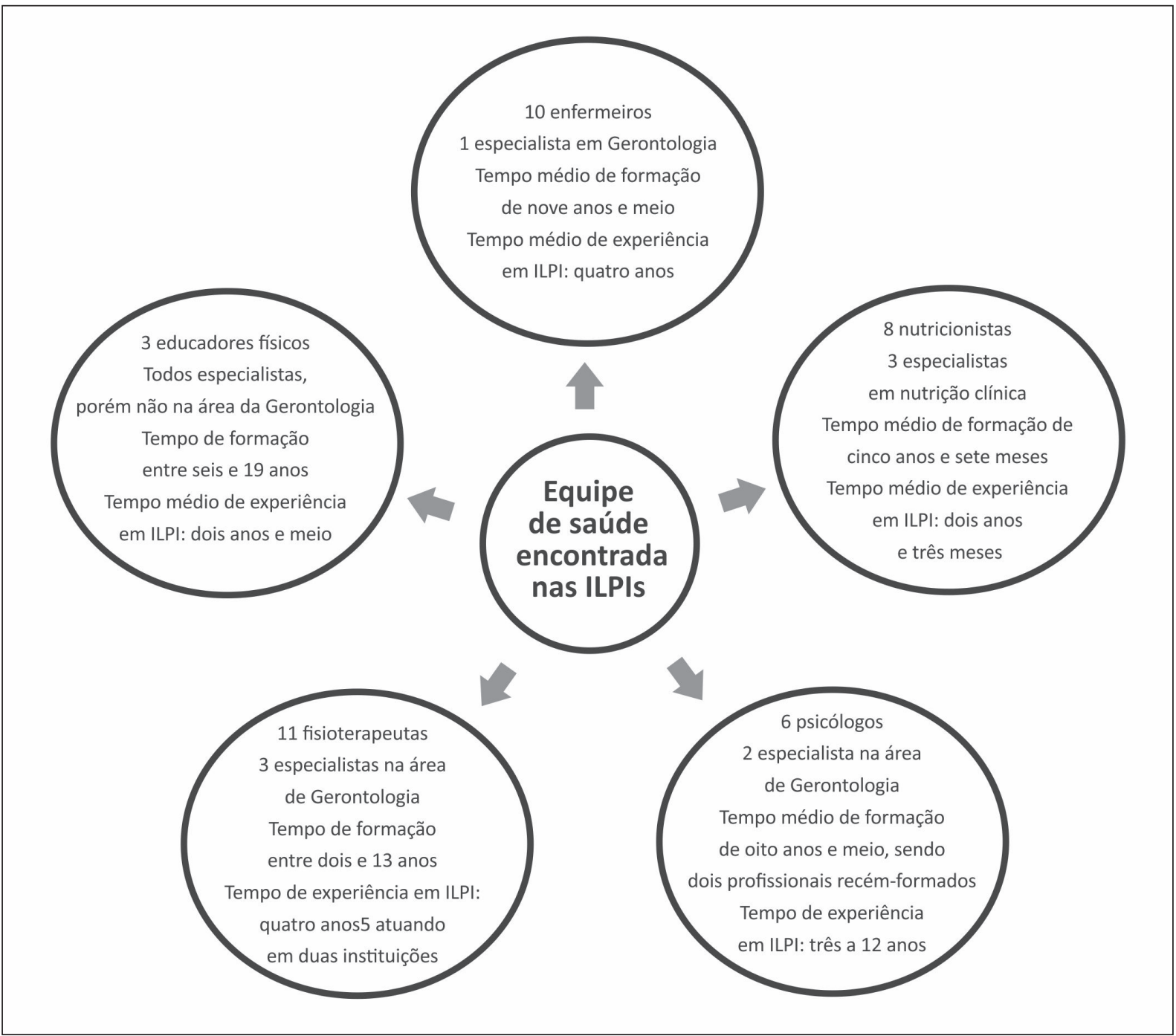

Figura 1. Caracterização das equipes de saúde das instituições de longa permanência para idosos. Passo Fundo-RS, 2013.

Aspecto importante demonstrado na figura 1 é quanto à composição da equipe multiprofissional, que ainda não é homogênea. Constata-se que o maior número de profissionais se dá entre os que desempenham a tarefa direta de cuidado e assistência, a cargo da equipe de enfermagem, que tem maior número de idosos sob sua atenção e maior número de horas de trabalho, o que está de acordo com pesquisas realizadas em ILPIs no Sul do Brasil. ${ }^{8,13}$

Isso se deve ao fato de a equipe de enfermagem, na sua estruturação de trabalhadores, possuir categorias de formação profissional de nível técnico. O educador físico é o profissional menos presente nesses cenários de cuidado, dado que 
contradiz os resultados da pesquisa realizada na Região Nordeste do país, onde o educador físico se faz presente em maior número de ILPIs. ${ }^{8}$

E ainda, a falta de trabalhadores qualificados em muitas ILPIs resulta na realização da maior parte do trabalho por auxiliares de enfermagem e/ou cuidadores, que foram ou ainda são profissionais responsáveis também por serviços gerais. ${ }^{15}$ Nesse sentido, além do número adequado de profissionais para a promoção da assistência ao idoso em ILPI, há de se considerar a expressiva importância de que estes estejam capacitados para ofertá-la com qualidade e eficiência.

\section{Desafios apontados pelos profissionais}

O trabalho de uma equipe nas ILPIs, de acordo com os profissionais que a compõem, revela em seu cotidiano situações das mais diversas ordens que, vistas como uma problemática que requer ações conjuntas, constituem desafios. Estes vão desde a gestão do serviço, sistematização das ações cuidativas, atendimento ao regulamento técnico das ILPIs, imagem desestimada do contexto da institucionalização até o fato de conviver e mediar conflitos. A figura 2 apresenta os desafios em primeiro plano, seguidos das situações apontadas pelos profissionais como geradoras dos mesmos.

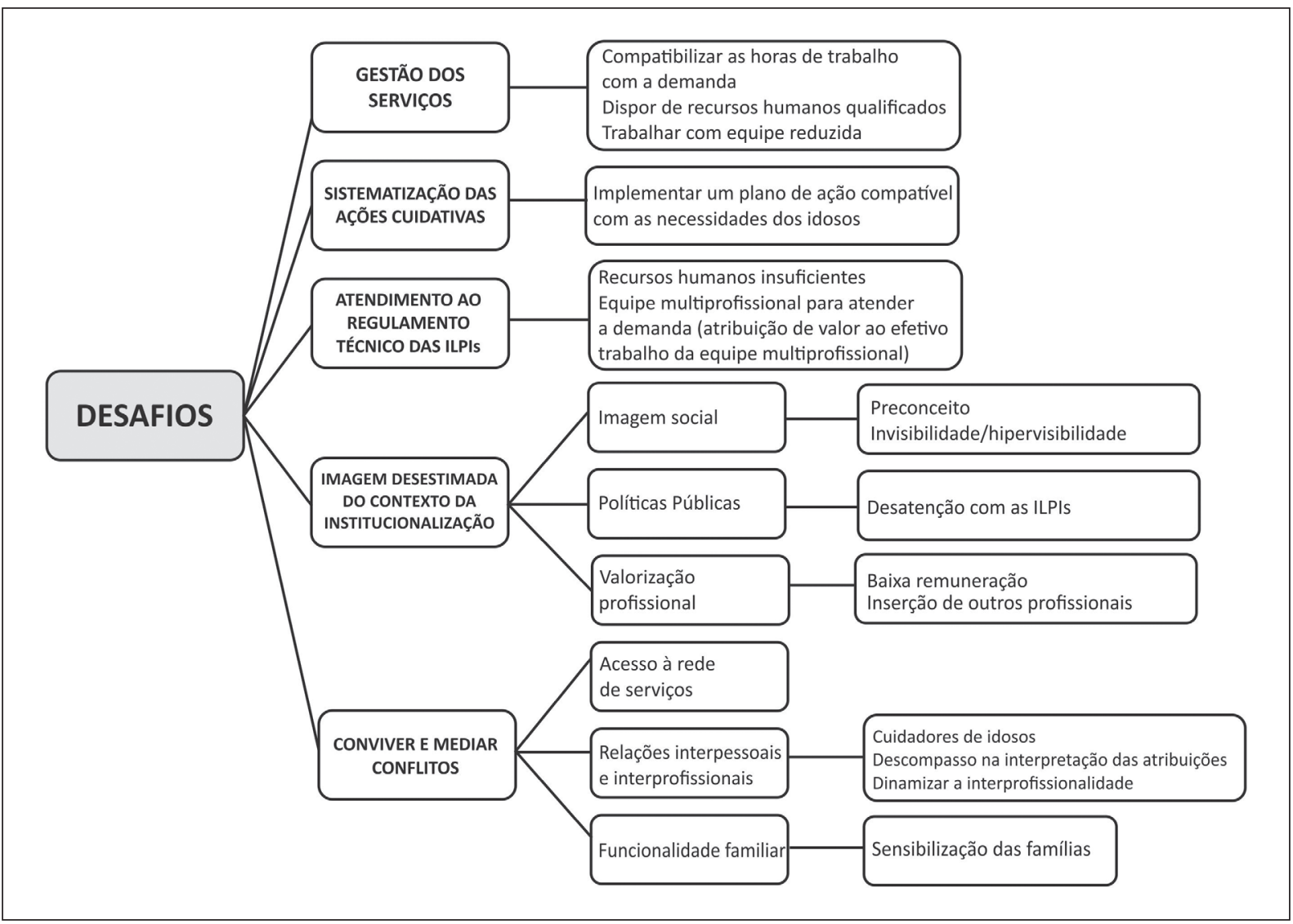

Figura 2. Diagrama dos desafios apontados pelos participantes. Passo Fundo- RS, 2013. 


\section{Gestão dos serviç̧os}

No que se refere aos desafios apontados pelos profissionais, expõe-se a dificuldade de gestão dos serviços nas ILPIs. Quanto à gestão, ${ }^{15}$ notase que o profissional que desempenha a função administrativa nem sempre tem formação ou capacitação técnica para exercer o cargo. O profissional que desempenha a função de administrador pode se deparar com dificuldades para manter uma equipe com recursos humanos suficientes para atender às necessidades dos idosos, associada à necessidade de ter de cumprir com a legislação. Segundo o depoimento:

Embora a legislação reconheça o profissional como parte atuante no corpo de profissionais de uma ILPI, não é isso que vemos na prática. O principal desafio é a falta de recursos financeiros o que faz o serviço ser muitas vezes realizado por mão de obra não qualificada. Também o pouco material disponivel e uma estrutura inadequada (fisioterapeuta).

Nesse sentido, os profissionais apontam como desafio da gestão cumprir o que prevê a legislação, ${ }^{4}$ estabelecendo que as ILPIs devem apresentar recursos humanos adequados e capacitados para desempenhar atividades de cuidado a saúde, lazer, limpeza e alimentação, adequando a quantidade de profissionais ao grau de dependência e número de idosos, além de dispor as horas de trabalho com as atividades a serem desenvolvidas. Depoimentos:

\footnotetext{
Íamos às ILPIs toda semana para realizar as atividades com idosos, quando foram cortados os convênios com a prefeitura nós não podemos mais frequentar as instituições. Sendo assim, as ILPIs ficaram sem profissionais da Educação Física, pois são poucas que têm condições financeiras para manter todos os profissionais (educador físico).
}

Mais horas para o trabalho em ILPIs diante da dificuldade em aumentar o peso dos idosos desnutridos e manter um bom estado nutricional (nutricionista).

Os achados encontrados em estudo realizado em ILPIs do Norte do país corroboram as necessidades encontradas em instituições do Sul do Brasil. ${ }^{16}$ Entende-se que a faixa etária dos mais velhos é pontuada por particularidades e, assim sendo, devem ser implementadas ações que visem adequar as equipes em termos de número de profissionais e capacitação dos recursos humanos, para melhor atenção aos idosos, refletindo na melhoria de sua qualidade de vida.

Vale ressaltar que o cotidiano do idoso residente em ILPI associa-se de forma direta ao planejamento e organização da instituição, que devem oportunizar mais do que os cuidados mínimos exigidos, como forma de qualificar a assistência. Nesse sentido, um dos desafios dos gestores é manter redes de suporte de prestação de serviços e programas existentes, não considerando somente o "fazer pelo asilo", mas o "fazer pelos asilados", o que suscita uma compreensão mais dedicada à natureza e ao funcionamento dos serviços. ${ }^{17}$

\section{Sistematização das ações cuidativas}

O envelhecimento é um fenômeno complexo, marcado por um período de transformações biológicas, psicológicas e sociais. ${ }^{8}$ Idosos institucionalizados frequentemente são pessoas portadoras de doenças crônicas, em condição de polifarmácia, ${ }^{18}$ que necessitam de vigilância nutricional, ${ }^{19}$ bem como de apoio psicológico no enfrentamento das situações inerentes à institucionalização. ${ }^{20}$ Essas intervenções devem ser compatíveis com as necessidades do idoso no seu plano multidimensional, ${ }^{21}$ o que só vem reforçar a importância de um caráter interdisciplinar na assistência, qualificando o serviço e mostrando respeito ao idoso, segundo o depoimento abaixo:

[...] é multidisciplinar, trabalhamos todos juntos... Através de trocas... Eu chego e a enfermeira vem me passar algo que aconteceu, on quando eu percebo passo... É troca de informações [...] o apoio psicológico ao idoso em sua nova situação de vida. Também o apoio aos familiares que demonstram muita ansiedade e angústia ao se desprenderem do idoso e o apoio à equipe de enfermagem e demais profissionais em suas dificuldades na compreensão do idoso e como conduzi-lo (psicóloga). 
O planejamento de ações exige que se siga a perspectiva da atenção gerontogeriátrica ${ }^{13} \mathrm{com}$ ações compatíveis com as necessidades do idoso, o que foi apontado pelos participantes do estudo como um desafio na atuação profissional dentro de uma ILPI. Vejamos os depoimentos a seguir:

Nas ILPIs, geralmente [os idosos] possuem severas limitações e não são estimulados a realizarem atividades que promovam funcionalidade. Geralmente permanecem em posturas fixas e não se locomovem se alguém não estimular (fisioterapeuta).

O papel da nutricionista é fundamental em ILPIs [...] desde o aproveitamento das doações, cuidados com esses alimentos desde que chegam, durante a manipulação e como são distribuidos (nutricionista).

Com relação ao profissional enfermeiro, há o entendimento de ser uma condição sine qua non a enfermagem se preparar técnica e cientificamente para a realidade não tão distante do envelhecimento populacional e as demandas de cuidado à saúde. ${ }^{15} \mathrm{O}$ profissional enfermeiro tem na Sistematização da Assistência de Enfermagem (SAE) uma importante ferramenta de trabalho, essencial para a prática da assistência, que qualifica e organiza o cuidado prestado. De fácil compreensão e eficaz para direcionar a atenção, ajuda a sistematizar ações voltadas ao cuidado do idoso. ${ }^{22}$

Estudo realizado com profissionais atuantes na Atenção Primária em Saúde, objetivando analisar a percepção dos mesmos quanto à saúde do idoso, demonstra que a atenção a essa faixa etária é complexa e deve ser pautada na integralidade; sobretudo, é necessário que haja constante investimento na capacitação dos profissionais, além de atenção baseada na visão multidimensional e interdisciplinar do idoso. ${ }^{23}$ O mesmo se pensa no panorama das ILPIs, como alternativa para suprir as carências dos profissionais, no que se refere a implementar um plano de ação compatível com as necessidades dos institucionalizados.

\section{Atendimento ao regulamento técnico das ILPIS}

Novamente ocupando papel de destaque na fala dos entrevistados, no que se refere aos desafios profissionais, figura a necessidade de cumprir os preceitos legais do regulamento técnico, para manutenção de recursos humanos capacitados e preparados para integrar uma equipe multiprofissional, que preste atenção efetiva e resolutiva no cuidado ao idoso.

Faz-se uma avaliação inicial do paciente no momento da institucionalização, aspectos cognitivos, história clínica e familiar. Esta avaliação é feita por cada profissional da respectiva área e é colocada em uma pasta que se chama PAI - plano de atendimento institucional (psicóloga).

As atividades são realizadas uma vez por semana, e tem duração de três horas semanais. Trabalhamos entre duas profissionais para desenvolver melhor as atividades (educador físico).

O Regulamento Técnico ${ }^{4}$ normatiza e é aplicado a todas as ILPIs, tendo por objetivo estabelecerum padrão mínimo de funcionamento, sendo que o não cumprimento constitui infração de natureza sanitária, estando o infrator sujeito a processo e penalidades previstas em lei. Neste estudo, os profissionais avaliaram haver insuficiência de recursos humanos, considerando as categorias dos participantes.

Outro desafio é que os idosos realizam os exercicios e manobras propostos pelo fisio somente durante as sessões. As ILPIs pecam na deficiência de pessoal para atendimento (fisioterapeuta).

Infelizmente não é bem assim, a maioria (das ILPIs) não tem educador físico [...] não é feita avaliação física. Tudo é feito pela percepção (educador físico).

Destacando a importância da interdisciplinaridade ${ }^{24}$ ressalta-se que a articulação da equipe multiprofissional engrandece o serviço prestado em uma ILPI e, além de garantir assistência de qualidade aos residentes, promove 
a valorização de recursos humanos qualificados nas instituições. A operacionalização da equipe, de forma interdisciplinar, ${ }^{25}$ promove o enfoque gerontológico nesses cenários, qualificando a atenção prestada ao idoso.

\section{Imagem desestimada do contexto da institucionalização}

Apontado como desafio para os profissionais atuantes em ILPIs, o estigma da institucionalização ainda se faz presente, refletindo o preconceito associado a uma imagem que remete à pobreza e ao abandono, já que as ILPIs constituem um universo marcado por doenças e limitações. O estigma associa-se também à finitude e ao entendimento de não trazer retorno à sociedade e à família, senão a perdas e morte. Essa representação contribui ainda mais para a manutenção de uma imagem social cercada por preconceitos. ${ }^{3}$

[...] a sensação de entrar nas ILPIs remete a um ambiente pesado, exige muito preparo mental e físico pra tá lá dentro e estar bem pra ter qualidade de vida [...] é trabalhar na questão de humanizar as ILPIs e conforme o conceito de instituição total (psicóloga).

Em estudo ${ }^{26}$ realizado para compreender a institucionalização através da percepção do idoso e de sua família, observou-se que a institucionalização é impulsionada por conflitos familiares, ausência de cuidador, comorbidades e vontade própria do idoso, e não somente por pobreza ou abandono, como se conjectura. A pesquisa aponta que o descumprimento das políticas públicas existentes e voltadas ao idoso se dá pela inadequação das mesmas à realidade da sociedade e da estrutura brasileira e pela falta de incentivo de órgãos públicos e do Estado.

$\mathrm{Na}$ complexidade da valorização dos profissionais, o próprio trabalhador é o ator essencial para elucidar os elementos que o fazem sentir-se um profissional valorizado. Depoimento:
Tem que ter inovação de poder questionar o serviço que a gente tá realizando [...] tem que olhar mais pra terceira idade, tem poucos profissionais que se interessam por isso. Dificilmente o profissional se qualifica para trabalhar com essa etapa que é esquecida, não se tem tanto contato na formação (psicóloga).

O protagonismo, a autonomia e a satisfação no trabalho são indicadores que refletem e engrandecem a atuação profissional. Transformações nos processos de trabalho, como melhoria das condições e adequada remuneração, bem como a inserção da equipe multiprofissional, só serão possíveis se as ações forem articuladas entre família, profissionais, gestores e sociedade, já que é necessário haver modificações culturais, sociais e comportamentais no que tange ao envelhecimento, atentando para a importância de um cuidado adequado e valorização dos profissionais atuantes no cenário do envelhecimento. ${ }^{20}$

\section{Conviver e mediar conflitos}

$\mathrm{Na}$ dinâmica do trabalho em equipe em uma ILPI, questões como o acesso a serviços, gestão de recursos, gerenciamento e mediação de conflitos aparecem na fala dos profissionais como desafios a serem enfrentados no cotidiano.

No que se refere a questões do gerenciamento do serviço e relações interprofissionais, ${ }^{27}$ o diálogo entre os membros da equipe multiprofissional, buscando consenso de ideias e esclarecimentos, já que as instituições necessitam de entrosamento entre a equipe de trabalho, seria uma forma coerente de minimizar conflitos.

O desafio é trabalhar com os funcionários, que nem sempre colaboram com as atividades desenvolvidas pela nutricionista devido a problemas na compreensão dos cardápios prescritos (nutricionista).

Assim, a família também deve estar envolvida e se posicionar no processo decisório sobre 
questões que envolvam a vida do idoso na instituição:

Mostrar aos familiares a importância da nutrição adequada para saúde do idoso [...] que no estágio de vida que se encontram necessitam de um acompanhamento nutricional, evitando carências de uma alimentação inadequada (nutricionista).

O cuidado prestado ao idoso em uma ILPI, por mais significativo que seja, não substitui aquele prestado pela família, ${ }^{12}$ sendo necessário que haja uma sensibilização da mesma, pois ela também será foco de atenção, já que a funcionalidade familiar tem papel significativo na execução do trabalho dentro da instituição. No entanto, é importante considerar que as ações que independem do núcleo de competência dos profissionais se tornam de responsabilidade de todos os membros da equipe. ${ }^{21}$

Perspectivas da equipe multiprofissional

acerca do trabalho em ILPIS

No que se refere às perspectivas, a fala dos profissionais se mostrou otimista, apontando a especialização em Gerontologia como uma especialidade emergente; a confiança no cumprimento dos preceitos legais para a implantação de uma equipe multiprofissional; a conscientização para a valorização profissional, além de mais programas apoiados pelo poder público nos cenários de cuidados de longa duração.

A figura 3 apresenta na fala dos profissionais as perspectivas apontadas na atuação em ILPIs.

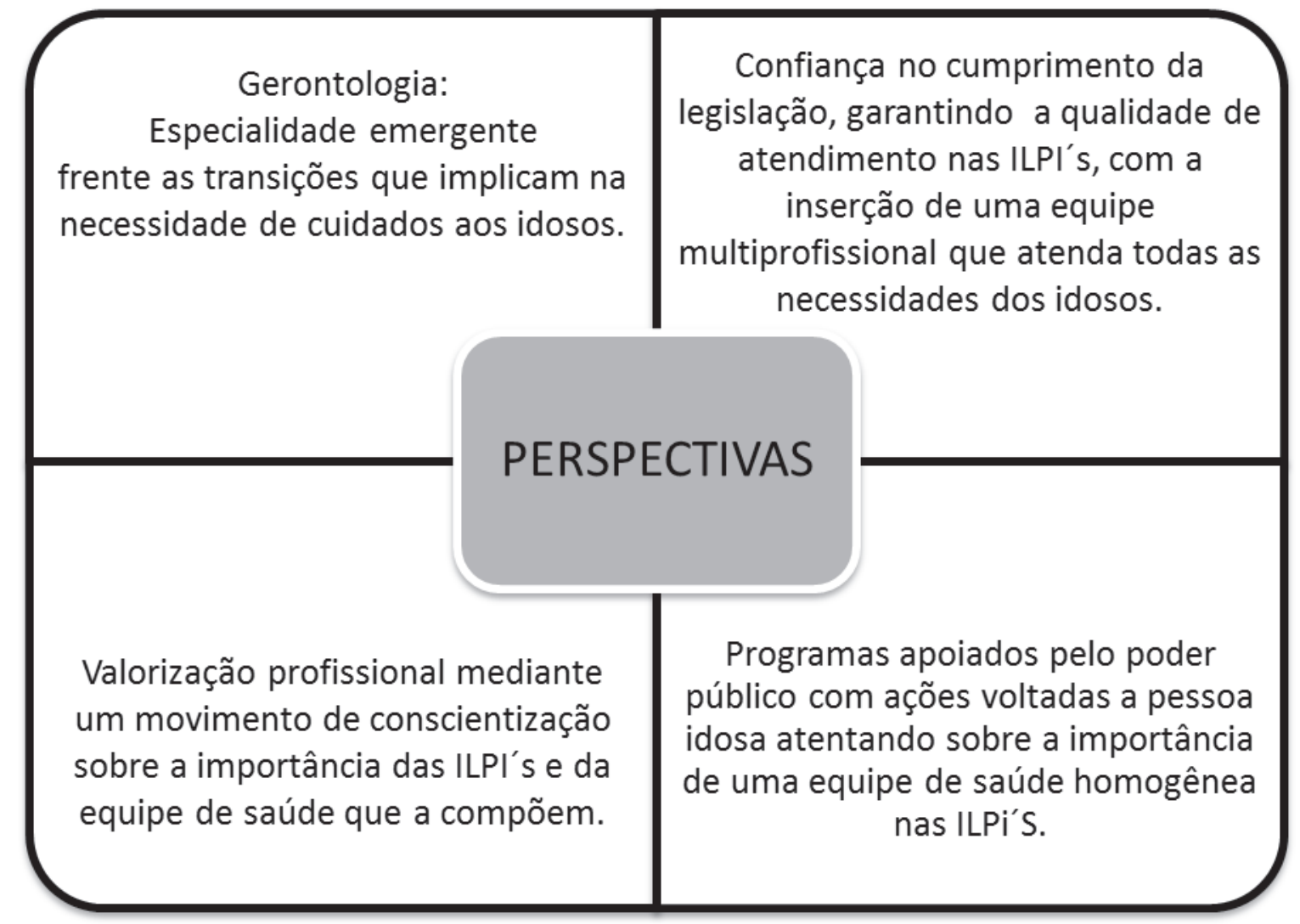

Figura 3. Diagrama das perspectivas apontados pelos participantes. Passo Fundo-RS, 2013. 
Gerontologia: uma especialidade emergente

A Gerontologia é um campo em expansão face às demandas do envelhecimento, ${ }^{5}$ pois a população idosa se apresenta com especificidades e necessidades que requer por parte dos profissionais das mais diferentes áreas do conhecimento a busca por essa formação específica, ${ }^{28}$ o que corrobora a posição dos entrevistados, como se observa nos depoimentos.

O futuro do Brasil vai ser os residenciais, pra quem tá se formando, quem pretende teria que ter uma especialização mais pra Geriatria [...] cada vez, vai crescer mais [...] é uma coisa assim que está em evidência [...] (enfermeiro).

Com o aumento da população de idosos e das ILPIs, esse mercado está em livre expansão; a procura tem crescido [...]. A atuação do fisioterapeuta nas ILPIs é de extrema importância, integrado à equipe multidisciplinar [...] (fisioterapenta).

A posição otimista dos entrevistados se dá pela compreensão de que a transição demográfica vem acompanhada de uma transição epidemiológica, o que implica uma demanda de cuidado para essa faixa etária. O cuidado que tradicionalmente ficava ao encargo da família, com as novas configurações contemporâneas, passa também a compor novos cenários, pois a população exposta a fragilidades típicas da idade nem sempre tem um cuidador familiar disponível. ${ }^{29}$ Para dar conta de uma atenção que possa suprir as necessidades, muitas famílias buscam nas ILPIs uma alternativa de cuidado. ${ }^{5}$

\section{Confiança no cumprimento dos preceitos legais}

Sobre os recursos humanos para a composição da equipe multiprofissional atuante nas ILPIs os entrevistados se mostram otimistas em relação ao futuro, acreditando que as possibilidades são viáveis desde que se cumpram os preceitos legais, como se observa nos relatos que seguem:

Acredito que deve ser aumentada a fiscalização para a obrigatoriedade da inserção do profissional nutricionista em ILPIs [...] Melhorias na normatização do trabalho do nutricionista em ILPIs, maior fiscalização, exigência da atuação deste profissional, aumento da quantidade de horas de trabalho do nutricionista em ILPIs (nutricionista).

Como futuro, vejo as ILPIs adaptadas $e$ regulamentadas, se empenhando nos serviços prestados aos idosos [...] existe a necessidade de aumentar a fiscalização nas instituições quanto aos serviços oferecidos (fisioterapenta).

Tem que a fiscalização bater nesses lugares e ir olhar e agir. [...] tem que ter uma preocupação de ter casas para idosos bem fiscalizadas, com pessoas responsáveis [...] Só o tempo vai fazer com que as coisas mudem. A cobrança do Conselho do idoso, da vigilância, da própria população, familiares, vão abrindo as portas e fazendo [...], mas no futuro vai ser melhor, eu acho (enfermeiro).

Estamos vivendo um momento de transição jurídica no que diz respeito ao reconhecimento do idoso como cidadão, ${ }^{30}$ no contexto de garantir direitos referentes à proteção e a assegurar cobertura às necessidades próprias dessa fase.

A posição dos entrevistados está alinhada com o Estatuto do Idoso ${ }^{31}$ no que se refere à garantia dos direitos fundamentais prevista nesse instrumento legal, mais especificamente o Art. 46, segundo o qual a política de atendimento ao idoso se fará por meio do conjunto articulado de ações governamentais e não governamentais da União, estados, Distrito Federal e municípios. Também com o Art. 50, no seu inciso V, que normatiza que é dever da instituição oferecer atendimento personalizado, e ainda com o inciso VIII, que o complementa no que diz respeito a proporcionar cuidados à saúde, conforme a necessidade do idoso. Por outro lado, os entrevistados têm discernimento sobre a competência, no que refere à fiscalização já prevista, no Art. 52, quando afirma que as entidades governamentais e não governamentais de atendimento ao idoso serão fiscalizadas pelos Conselhos do Idoso, Ministério Público, Vigilância Sanitária e outros previstos em lei. 
Valorização profissional mediante

um movimento de conscientização

Apesar de o número de ILPIs no Brasil estar aumentando, ainda é um universo repleto de preconceitos, em que as instituições muitas vezes são consideradas como "depósito" de pessoas, e aquele que atua nesses cenários está ali por falta de outra alternativa. ${ }^{8}$ Logo, entende-se que os próprios profissionais inseridos nesse campo de atenção são os responsáveis pela mudança de paradigma, como se observa nas falas:

Vejo boas perspectivas, pois os profissionais estão valorizando a nutrição e abrindo portas para a atuação deste profissional poder aplicar seus conhecimentos. Observo a inserção do profissional com otimismo para o futuro. Acredito que o profissional terá maior valorização no futuro e não será contratado somente por obrigação (nutricionista).

Como perspectiva futura, temos muito que lutar $e$ conscientizar tanto familiares quanto as ILPIs de que este é um serviço indispensável dentro da instituição e que com ele todos têm a ganhar (fisioterapeuta).

Para que ocorra uma reorganização do processo de trabalho e uma maior valorização ${ }^{32}$ dos sujeitos que constituem a equipe de saúde das ILPIs, é necessário promover uma formação profissional coerente ao contexto social contemporâneo, pautado na responsabilidade e no comprometimento com as questões emergentes da longevidade, juntamente com ações de educação permanente, para que os próprios profissionais sejam capazes de realizar modificações nas dinâmicas pertinentes ao exercício profissional. $O$ engajamento das relações sociais entre equipe, usuários e gestores de saúde organiza e conduz os serviços a propiciar mudanças, tornando o trabalho cada vez mais qualificado.

\footnotetext{
A gente tem que abrir esse campo, mostrar como pode ser feito isso. Conquistar esse espaço na sociedade e que a sociedade perceba isso. Abrir espaço também entre os demais profissionais (psicólogo).
}

Entende-se que, para suprir as necessidades no que se refere à demanda de cuidado, deve haver uma equipe multiprofissional capaz de desenvolver suas atividades visando uma atenção integral. ${ }^{5}$

\section{Mais programas apoiados pelo poder público}

Os entrevistados demonstraram sentir necessidade de iniciativas governamentais que garantam não somente a garantia da inserção dos profissionais em atuação nas ILPIs, mas também entendem a importância de ações voltadas à saúde da pessoa idosa.

\section{O município deveria olhar mais para esse lado e valorizar [...]. Quando foram cortados os convênios com a prefeitura, deixamos de frequentar as instituições [...] (educador físico). \\ O mercado ainda é amplo, no entanto, entendo que enquanto não houver um maior incentivo por parte do governo e políticas públicas para os idosos alertando para a necessidade não será possivel expandir (fisioterapeuta).}

As ILPIs não contam com programas e iniciativas do poder público, voltados exclusivamente para a manutenção das mesmas. No ano de 2006, o Pacto pela Saúde apresentou diretrizes sobre a saúde da pessoa idosa. A Política Nacional de Saúde da Pessoa Idosa ${ }^{33}$ direcionou medidas coletivas e individuais para a manutenção e a autonomia dos indivíduos idosos, prevendo superar o pequeno número de equipes multiprofissionais e interdisciplinares que tenham experiências no âmbito do envelhecimento e na saúde do idoso.

Nas gestões municipais, verifica-se a dificuldade de operacionalizar políticas públicas de acordo com as necessidades locais, voltadas aos idosos. A inviabilidade está no fato de que, muitas vezes, a governabilidade sofre interferências, não permeadas em questões éticas e técnicas, dificultando a implantação de políticas públicas intersetoriais. ${ }^{34}$ 
As potenciais limitações do estudo centramse no fato de explorar uma realidade específica, envolvendo um número restrito de instituições, em que, das 14 participantes, apenas duas eram filantrópicas e nessas a composição das equipes de saúde sofreu variação em relação às ILPIs privadas com fins lucrativos. Apesar de os achados evidenciarem as peculiaridades de um contexto regional, no Sul do Brasil, o que restringe a generalizações para outros cenários, o estudo contribui para o debate da formação de recursos humanos na área da Gerontologia.

\section{CONSIDERAÇÕES FINAIS}

Os cenários de cuidado de longa duração, a exemplo das ILPIs, na atualidade, estão se ajustando às normas e regulamentos técnicos em vigor, o que indica também um ajustamento no quadro de recursos humanos. O estudo mostrou que o predomínio da equipe está centrado no cuidado das necessidades básicas dos idosos. Os desafios pontuados são da ordem de gestão do serviço, sistematização das ações cuidativas, atendimento ao regulamento técnico das ILPIs, imagem desestimada do contexto da institucionalização e convivência e mediação de conflitos. Esses desafios podem ser superados, em uma perspectiva futura positiva, a partir de um trabalho multidisciplinar.

\section{REFERÊNCIAS}

1. Brasil. Ministério da Saúde, Secretaria de Atenção à Saúde, Departamento de Ações Programáticas e Estratégicas. Atenção à saúde da pessoa idosa e envelhecimento. Ministério da Saúde: Brasília, DF; 2010. (Série B. Textos Básicos de Saúde); (Série Pactos pela Saúde, vol. 12)

2. Vasconcelos AMN, Gomes MMF. Demographic transition: the brazilian experience. Epidemiol Serv Saúde 2012;21(4):539-48.

3. Camarano AA, Kanso S, Mello JL, Carvalho DF. As instituições de longa permanência para idosos no brasil. In: Camarano AA, organizadora. Cuidados de longa duração para a população idosa : um novo risco social a ser assumido? Rio de Janeiro: Ipea; 2010. p. 187-212.
Nesse sentido, acreditam que no futuro a gestão desses espaços consiga manter uma equipe multiprofissional mais homogênea, mesmo que seja no cumprimento dos preceitos legais, que por sua vez resultará em benefício da população atendida.

Contudo, constata-se ainda a dificuldade de definição acerca do financiamento das ILPIs, permeando questões tangentes ao caráter dessas instituições, pois as mesmas prestam serviço de assistência social, bem como serviços de saúde, o que na legislação também não está definido. Logo, chama a atenção para o fato de nenhuma das 14 ILPIs participantes do estudo ter como integrante da equipe multiprofissional o profissional assistente social.

Sugere-se que mais estudos sejam realizados explorando esse tema, utilizando outros métodos e ampliando a pesquisa a outras realidades. Desse modo, a avaliação das diversas características das ILPIs, diferenciando instituições filantrópicas de particulares, avaliando pelo grau de dependência dos idosos ou pelo vínculo empregatício dos profissionais da instituição, seriam questões que embasariam próximas pesquisas. Logo, também seria importante replicar novos estudos em outros cenários de atenção ao idoso.

4. Brasil. Agência Nacional de Vigilância Sanitária. RDC $\mathrm{n}^{\circ} 283$, de 26 de setembro de 2005. Regulamento técnico para o funcionamento das instituições de longa permanência para idosos. Brasília, DF: ANVISA; 2005.

5. Silva BT, Santos SSC. Cuidados aos idosos institucionalizados: opiniões do sujeito coletivo enfermeiro para 2026. Acta Paul Enferm [Internet] 2010 [acesso em 20 jun 2013];23(6):775-

81. Disponível em: http://www.scielo.br/ scielo.php?script=sci_arttext\&pid=S0103$21002010000600010 \& \operatorname{lng}=$ en\& $\mathrm{nrm}=$ iso.

6. Watanabe HAW. Atenção ao Idoso em Intituições de Longa Permanência. In: Domingues MA, Lemos ND. Gerontologia: os desafios nos diversos cenários da atenção. Barueri: Manole; 2010. p. 470. 
7. Pollo SHL, Assis M. Instituições de longa permanência para idosos- ILPIS: desafios e alternativas no município do Rio de Janeiro. Rev Bras Geriatr Gerontol [Internet] 2008 [acesso em 20 mar 2014];11(1):29-44. Disponível em: http://revista.unati.uerj.br/scielo.php?script $=$ sci_ arttext\&pid=S1809-98232008000100004\&lng=pt.

8. Cristophe M. Instituições de Longa Permanência para Idosos no Brasil: uma opção de cuidados de longa duração? [dissertação]. Rio de Janeiro: Escola Nacional de Ciências Estatísticas; 2009.

9. Telles JL, Borges APA. Interdisciplinaridade e trabalho em equipe na abordagem da pessoa idosa nos serviços de atenção básica em saúde. In: Malagutti W, Bergo AMA, organizadores. Abordagem Interdisciplinar do Idoso. Rio de Janeiro: Rubio; 2010.

10. Piexak DR, Freitas PH, Backes DS, Moreschi C, Ferreira CLL, Souza MHT. Percepção de profissionais de saúde em relação ao cuidado a pessoas idosas institucionalizadas. Rev Bras Geriatr Gerontol 2012;15(2):201-8

11. Geniole, LAI, Kodjaoglanian VL, Vieira CCA, Da Costa KC. Organizadores. Assistência multidisciplinar à saúde. Vol. 3. Campo Grande, MS: UFMS/ Fiocruz Unidade Cerrado Pantanal; 2011.

12. Creutzberg M, Gonçalves LHT, Dos Santos BL, Santos SSC, Pelzer MT, Portella MR, et al. Acoplamento estrutural das instituições de longa permanência para idosos com sistemas societais do entorno. Rev Gaúch Enferm 2011;32(2):219-25

13. Camarano AA, coordenadora. Características das Instituições de Longa Permanência para Idosos: Região Sul. Brasília: IPEA; 2008.

14. Bauer MW. Análise de conteúdo clássica: uma revisão. In: Bauer MW, GASKELL G, editores. Pesquisa qualitativa com texto, imagem e som: um manual prático. $8^{\mathrm{a}}$ ed. Pedrinho Guareschi, tradutor. Petrópolis: Vozes; 2010. p. 189-217.

15. Santos SSC, Silva BT, Barlem ELD, Lopes RS. O papel do enfermeiro na instituição de longa permanência para idosos. Rev Enferm UFPE On Line [Internet] 2008 [acesso em 20 jun 2013];2(3):2628. Disponível em: http://repositorio.furg.br:8080/ jspui/bitstream/1/1537/1/PDF\%20n\%C2\%BA\%20 18.PDF.

16. Angelo BHB, Silva DIB, Lima MAS. Avaliação das instituições de longa permanência para idosos do município de Olinda-PE. Rev Bras Geriatr Gerontol [Internet] 2011 [acesso em 11 jun 2013];14(4):66373. Disponível em: http://revista.unati.uerj. br/scielo.php?script $=$ sci_arttext\&pid=S180998232011000400006\&lng=pt.
17. Moura GA, Souza LK. Práticas de lazer na ILPI: a visão dos coordenadores. Licere 2014;17(3):1-43.

18. Lucchetti G, Granero AL, Pires SL, Gorzon ML. Fatores associados à polifarmácia em idosos institucionalizados. Rev Bras Geriatr Gerontol [Internet] 2010 [acesso em 11 jun 2013];13(1):518. Disponível em: http://revista.unati.uerj.br/ scielo.php?script $=$ sci_arttext\&pid $=$ S180998232010000100006\&lng=pt.

19. Nobre MT, Nunes MMF. Avaliação antropométrica de idosos residentes em instituições de longa permanência de Fortaleza-CE. Rev Bras Geriatr Gerontol [Internet] 2010 [acesso em 11 jun 2013];13(2):235-44. Disponível em: http:// revista.unati.uerj.br/scielo.php?script $=$ sci_ arttext\&pid=S1809-98232010000200008\&lng=pt.

20. Anacleto MIC, Souza AS, De Angelis G, Pereira MP. A mortificação do eu: vivências psicológicas de idosos institucionalizados. Rev SPAGESP [Internet] 2004 [acesso em 11 jun 2013];5(5):50-5. Disponível em: http://pepsic.bvsalud.org/scielo.php?script=sci_ arttext\&pid=S1677-29702004000100009\&lng=pt.

21. Silva ARB, Yamamoto CMK, Fernandes RG. Atenção ao idoso em instituições de longa permanência: o enfoque da fonoaudiologia. In: Domingues MA, Lemos ND. Gerontologia: os desafios nos diversos cenários da atenção. Barueri: Manole; 2010. p. 495 508.

22. Santos SSC, Da Silva BT, Barlem ELD, Lopes RS. O papel do enfermeiro na instituição de longa permanência para idosos. Rev Enferm UFPE On Line [Internet] 2008 [acesso em 11 jun 2013];2(3):2628. Disponível em: http://repositorio.furg.br:8080/ jspui/bitstream/1/1537/1/PDF\%20n\%C2\%BA\%20 18.PDF.

23. Marin MJS, Marques APM, Feres BOM, Saraiva AKH, Druzian S. A atenção à saúde do idoso: ações e perspectivas dos profissionais. Rev Bras Geriatr Gerontol [Internet] 2008 [acesso em 11 jun 2013];11(2):245-258. Disponível em: http:// revista.unati.uerj.br/scielo.php?script $=$ sci_ arttext\&pid=S1809-98232008000200009\&lng=pt.

24. Yoshitome AY. Atenção ao idoso em instituições de longa permanência: o enfoque da Enfermagem. In: Domingues MA, Lemos ND. Gerontologia: os desafios nos diversos cenários da atenção. Barueri: Manole; 2010. p.471-6

25. Luppi G, Carvalho MFC. Atenção ao idoso em instituições de longa permanência: o enfoque da Farmácia. In: Domingues MA, Lemos ND. Gerontologia: os desafios nos diversos cenários da atenção. Barueri: Manole; 2010. p.477-86. 
26. Dias IG. A institucionalização asilar na percepção do idoso e de sua família: o estudo do "lar dos velhinhos” - Viçosa/MG [dissertação]. Viçosa: Universidade Federal de Viçosa; 2007.

27. Creutzberg M, Gonçalves LH, Sobottka EA, Ojeda BS. Long-term care institutions for elders and the health system. Rev Latinoam enferm 2007;15(6):1144-9.

28. Sá JLM. A formação profissional em gerontologia. In: Freitas EV, organizador. Tratado de geriatria e gerontologia. $3^{\mathrm{a}}$ ed. Rio de Janeiro: Guanabara Koogan; 2011. p. 1741.

29. Camarano AA. Conclusão: cuidados de longa duração para a população idosa: um novo risco social a ser assumido? In: Camarano AA, organizadora. Cuidados de longa duração para a população idosa: um novo risco social a ser assumido?Rio de Janeiro: IPEA; 2010.

30. Faleiros VP. Cidadania e direitos da pessoa idosa. Ser Soc 2007;(20):p. 35-61.
31. Brasil. Lei n. ${ }^{\circ}$ 10.741, de $1^{\circ}$ de outubro de 2003. Dispõe sobre o Estatuto do idoso e dá outras providências. Diário Oficial da União. Brasília, DF. 3 out 2003, Seção 1, p. 1.

32. Santos-Filho SB. Indicadores de valorização do trabalho e trabalhadores da saúde: construindo o conceito de valorização a partir de uma perspectiva analítica. In: Santos-Filho SB, Barros MEB, organizadores. Trabalhador da saúde: muito prazer! Protagonismo dos trabalhadores na gestão do trabalho em saúde. Ijuí: Unijuí; 2007. p.143-71.

33. Brasil. Portaria n. ${ }^{\circ} 2.528$ de 19 de outubro de 2006. Política Nacional de Saúde da Pessoa Idosa (PNSPI). Diário Oficial da União. Brasília, DF. 20 out 2006, Seção 1, p. 142.

34. Brêtas ACP. Cuidadores de idosos e o Sistema Único de Saúde. Rev Bras Enferm 2003;56(3):298-30. 